\title{
CORTISONE AND ITS ANALOGUES IN THE NEPHROTIC SYNDROME
}

\author{
By G. A. SmarT, B.Sc., M.D., F.R.C.P. \\ Professor of Medicine in the University of Durham
}

If ACTH, cortisone, hydrocortisone, prednisone or prednisolone is given in appropriate doses for two or three weeks to a patient suffering from the nephrotic syndrome, it is sometimes accompanied or followed by a series of events, the most striking of which (as noted by Farnsworth, 1950) is a profuse diuresis. Less often, however, there is in addition a cessation of proteinuria. It is proposed to outline the method of therapy and the changes which may follow it, and to discuss the possible mode of action.

\section{Definition and Description of the Nephrotic Syndrome}

The nephrotic syndrome is characterized by proteinuria, oedema associated with low serum albumen, and a high level of serum lipids. There are many conditions, however, which can give rise to this concatenation, in particular subacute nephritis or Type II nephritis (Ellis, I942), 'pure' neprosis, thrombosis of the renal arteries, amyloid disease of the kidney, lupus erythematosis affecting the kidneys, and diabetic intercapillary glomerulosclerosis (Kimmelsteil and Wilson, 1936). One usually has other evidence to suggest that a renal lesion might be due either to amyloidosis, to lupus erythematosis or to intercapillary glomerulosclerosis, and generally, though not always, there may be signs or a history suggestive of inferior vena caval or renal vein thrombosis. It may be quite impossible, however, to distinguish 'pure' nephrosis from the nephrotic stage of subacute nephritis-indeed Ellis (1942) feels that the former is merely an early stage of the latter. It would seem that further elucidation of this problem may come from the use of needle renal biopsy, especially in the early stages (Bjфrneboe, Brun, Gormsem, Iversen and Raaschou, 1952; Kark, Muehrcke, Pirani and Pollak, 1955). Meanwhile, however, we must group together a series of oedematous, albuminuric, hypoalbuminaemic patients who have no evidence of the specific lesions mentioned above, who have no evidence of permanent nitrogen retention or other evidence of renal failure and who do not exhibit pathological hypertension. Not only is it known from the natural history of such patients, that they are liable to undergo remissions and relapses apparently spontaneously but they also appear to remit or relapse as a result of infections, relapse being far more common after those of the upper respiratory tract, whereas more serious infections tend to be followed by remissions. These remissions usually consist of a diuresis and consequent removal of oedema, but at times they are also associated with a complete cessation of proteinuria and apparent cure. It is not possible from a review of the literature to determine how often this happens, for nobody is agreed if or how one can differentiate 'pure nephrosis' from 'subacute nephritis in the nephrotic stage' and different authors present very different statistics depending largely upon the ages of their patients. Thus Ellis (1942) found that only 5 of his 145 cases recovered completely-most of the cases were adults-whereas Fanconi et al. (195I) and Barness, Moll and Janeway (1950), reported a presumed cure rate of about 30 per cent.

\section{The Indications for Treatment with Corticoids}

The precise indications for the use of hormones in the nephrotic syndrome have not been fully determined. In the author's experience, however, patients with the nephrotic syndrome resulting from disseminated lupus, from amyloidosis or from Kimmelsteil-Wilson lesions have never shown any satisfactory response and one would not anticipate any therapeutic effect in those with renal vein thrombosis. It also seems to have been the general experience that patients, who show definite evidence of prolonged and constant nitrogen retention, do not respond. The results of the work carried out at Newcastle (Charlton; Latner, Platt, Smart, Thompson and Walker, 1958) would also suggest that, although statistically there is evidence that most patients with the nephrotic syndrome have a blood pressure somewhat above the mean for subjects of similar age 
TABLE I

RESPONSE WITH REGARD TO B.P.

Mean equivalent deviation of blood pressure in $\mathrm{mm}$. $\mathrm{Hg}$. from the population average (Hamilton et al., 1954)

\begin{tabular}{lll|c|c|c}
\hline \multicolumn{2}{c}{ Response to } & ACTH & $\begin{array}{c}\text { Number of } \\
\text { patients }\end{array}$ & Systolic & Diastolic \\
\hline Complete & $\ldots$ & $\ldots$ & 7 & $+13.6 \pm 8.84$ & $+15.0 \pm 6.55$ \\
\hline Partial $\ldots$ & $\ldots$ & $\ldots$ & 5 & $+27.0 \pm 7.68$ & $+18.0 \pm 5.62$ \\
\hline None $\ldots$ & $\ldots$ & $\ldots$ & 5 & $+56.0 \pm 11.00$ & $+19.0 \pm$ 1 1.78 \\
\hline
\end{tabular}

and sex, those with the higher systolic pressures are less likely to respond than those in whom it is not so raised (Table $\mathrm{r}$ ).

Thus, treatment with ACTH or appropriate steroid hormones is worth trying in those patients with the nephrotic syndrome when this is not associated with lupus erythematosis, amyloidosis, renal vein thrombosis or inter-capillary glomerulosclerosis, when there is no long-continued and marked nitrogen retention and when the blood pressure is not unduly elevated.

\section{The Schedule of Treatment}

Details of treatment as practised by various workers have varied, but the suggestions given are based on personal experience and are largely in agreement with the methods used by workers who have obtained the best results.

Before and during the hormone therapy it is best to give penicillin or a wide spectrum antibiotic as prophylaxis against any generalized pyogenic infection. Patients with the nephrotic syndrome are very liable to such infections, presumably because of the serious depletion of $\gamma$-globulins and hence of immune bodies which are lost in the urine. When glucocorticoid hormones are given this increases still further the liability to spread of infections and thus arises the need for antibiotic prophylaxis.

If ACTH or cortisone are used the patients should be put on a low sodium diet. With these hormones there is a distinct liability to sodium retention and the oedema may increase to an undesirable extent unless the sodium intake is kept very low. When prednisone or prednisolone are used sodium retention is not so marked so that its restriction in the diet is not so important.

Careful observations relative to extracellular potassium levels should be made. Preferably the serum potassium concentration should be measured at least every other day and, if it falls, supplements of potassium chloride or citrate should be given in amounts appropriate to maintain a normal serum concentration. This will vary from 0.5 to 3 or more g. of potassium per day in addition to that which is ingested with the food. Even though there may be no evidence of renal failure, these supplements may cause a dangerous rise in serum $\overrightarrow{0}$ potassium concentration, hence careful bio- 3 chemical control is necessary throughout the $\omega$ treatment and until the full effect of the treatment $\dot{\omega}$ has become manifest. If serum potassium estimations are difficult to obtain then, as a second best, an E.C.G. should be done at least every other day, since this will reveal the likelihood of any gross potassium abnormalities. Blood ureas should be estimated throughout therapy since occasional cases have been noted where this has become seriously raised.

The hormones should be used in fairly large cु doses. ACTH should be given at a dose of now. less than 80 i.u. (long-acting) per 24 hours to a adult and at times a larger amount may be necessary. Cortisone should be given to an adult at a dose of not less than $25 \mathrm{mg}$. $4 \mathrm{x}$ per day and sometimes twice that amount may be given. Prednisone or prednisolone may be given in initial doses of about $60 \mathrm{mg}$. per day (Arneil, 1956). In infants and very young children somewhat smaller doses may be given, but it is the author's general experience that they need, on the whole, to be very little less than those given to adults.

These hormones should be given if necessary for two to three weeks and they should then be stopped. This can be done abruptly in the case of ACTH but it is as well to decrease the dose over a period of a few days with the other substances. It has been claimed that prolonged therapy in patients who have not fully responded may ultimately give a good result, but this has not been borne out in the author's personal experience. It may be, however, that in patients who have a definite tendency to relapse long-continued therapy with relatively small doses of prednisone or prednisolone may be beneficial in preventing these relapses (Lange, Slobody and Strang, 1953; Merrill, Wilson and Timberlake, 1954 and Debre, Royer and Minor, 1956). 
TABLE 2

Present Protein in Relation to Initial Response

Present status of nephrotics treated in Newcastle series in relation to the initial response to ACTH

\begin{tabular}{|c|c|c|c|c|c|c|}
\hline $\begin{array}{l}\text { Initial response } \\
\text { to } A C T H\end{array}$ & $\begin{array}{l}\text { Total No. } \\
\text { of patients }\end{array}$ & $\begin{array}{l}\text { Well and free } \\
\text { from proteinuria } \\
\text { and oedema }\end{array}$ & $\begin{array}{l}\text { Proteinuria } \\
\text { no oedema } \\
\text { no renal frilure }\end{array}$ & $\begin{array}{l}\text { Proteinuria and } \\
\text { oedema no renal } \\
\text { failure }\end{array}$ & $\begin{array}{l}\text { Signs of } \\
\text { renal failure }\end{array}$ & Dead \\
\hline Complete & 17 & 15 & $\mathbf{I}$ & I & $\circ$ & $\circ$ \\
\hline Partial .. & 14 & $\mathbf{I}$ & 6 & $\mathbf{I}$ & 3 & 3 \\
\hline None & 6 & 0 & $\mathbf{I}$ & $\mathbf{I}$ & 3 & I \\
\hline
\end{tabular}

\section{The Effects of Treatment}

Although correct statistical evaluation of this form of therapy has never been carried out and although without it judgement is difficult owing to the natural tendency to spontaneous remission, it is generally accepted that ACTH and glucocorticoids is the treatment of choice in suitable cases. It is indeed difficult to justify the complete withholding of such treatment since, although a full response is often not obtained, a diuresis during or within a few days of the cessation of therapy is a frequent occurrence. In the Newcastle series a diuresis occurred ten times as frequently after ACTH as during the previous control periods of observation.

Whilst the hormone is being given there may be some increase in body weight due to sodium and water retention and some degree of ' moon face' may develop. In addition the blood pressure may become unduly elevated and this entails a reduction in dosage. The very occasional effect on blood urea has already been mentioned.

Between about the tenth day of treatment and the fifth or sixth day after therapy has been discontinued, in a large proportion of patients a diuresis will occur. This may be very dramatic indeed and result in a loss of all the oedema. Together with the water loss there is also a considerable loss of sodium and chloride and of potassium (during the diuresis there is sometimes an increased tendency for the serum potassium concentration to fall). At the end of such a diuresis the full degree of emaciation as it occurs in this syndrome may be seen, since it is no longer masked by the generalized oedema. There is a tendency, particularly in children, for the appetite at this stage to become voracious and the weight may begin to increase. Sometimes this is due to a re-accumulation of extra-cellular fluid, but in the more satisfactory cases the weight gain is more probably due to an increase in muscle and tissue mass.

In a smaller proportion of cases (about one-third in some series) the proteinuria completely disappears and, although relapse may occur, this will usually again respond satisfactorily to treatment.
The results so far in the Newcastle cases are very much better in patients who were rendered free from proteinuria by treatment than in those who only had a diuresis or who had no response at all (Table 2).

Serial electrophoresis of the plasma proteins shows that initially the concentrations of albumen and of $\gamma$ globulins are very low, whereas that of the $\alpha_{2}$ globulin is very high. During therapy there is an increase in the albumen concentration and some decrease in that of the $\alpha_{2}$ globulin. These trends, however, continue for some time after therapy has been discontinued and a period of months may elapse, even in patients rendered free from proteinuria, before the concentrations of the plasma protein fractions return to normal.

In addition it has been shown by Soshea and Farnsworth (195I) that the lipaemia which is such a feature of the nephrotic syndrome may be strikingly diminished during the early part of hormone therapy.

\section{Mode of Action}

There is no unanimity of opinion concerning the mode of action of these hormones. The production of a diuresis being the most striking response, it was at first thought that the main effect might be produced by suppression of the adrenal cortex-either when cortisone was given, or just after the cessation of ACTH when it would no longer be stimulated. In support of this could be quoted the findings of Leutscher et al. (1953) and of Metcoff et al. (I95 I) who noted the presence of large amounts of a sodium-retaining substance (aldosterone) in the urine of nephrotic patients with a fall in its secretion during diuresis. Curiously enough, however, ACTH probably has little effect on aldosterone secretion and a diuresis is often observed whilst ACTH is being given.

The increase in serum albumen which (in spite of earlier reports to the contrary) occurs during ACTH therapy would suggest that fluid is thereby transferred from the interstitial spaces into the circulation. This is supported by the fall in haemoglobin concentration which occurs before the diuresis. Measurements of plasma volumes 
have, however, given somewhat variable results. The increased circulating blood volume might result in an increased glomerular filtration rate and this has indeed been found to occur during hormone therapy (Metcoff et al., 1951). The increased G.F.R. could conceivably result in the sodium diuresis which is observed to occur. There is much evidence, however, that there is not an essential mechanism, for many patients with untreated 'nephrosis' have been found to have a normal G.F.R. (Bruck et al., 1954) and an increase is not an essential preliminary to a diuresis.

Lange, Graig, Oberman, Slobody, Ogur and IoCasto (195I) and others consider that the nephrotic syndrome results from an antigenantibody reaction involving the glomerular basement membrane. A very similar picture can be produced experimentally with nephrotoxic serum (Masugi, 1933-34) and Lange et al. (195I) find that the serum complement is low during relapse and rises as a remission occurs. In this view ACTH and the glucocorticoids would act by interfering in some way with the antigen-antibody reaction. As yet, however, there has been no substantiated evidence of antibodies to human glomeruli in the plasma of nephrotic patients.

\section{Conclusion}

In suitable patients, who exhibit the nephrotic syndrome, it is always worth while to try the effect of ACTH, cortisone, hydrocortisone, prednisone or prednisolone, provided suitable precautions are taken. A diuresis will frequently be obtained and this at least will make the patient $\vec{Q}$ good deal more comfortable. In addition, how气 ever, a number of patients will become free from all proteinuria and the prognosis in such cases would appear to be quite good.

\section{BIBLIOGRAPHY}

ARNIEL, G. C. (1956), Lancet, i, 409.

BARNES, L. A., MOLL, G. H., and JANEWAY, C. A. (1950) Pediastrics, 5, 486.

BJORNEBOE, M., BRUN, C., GORMSEM, H., IVERSEN, $P$ ग and RAASCHOU, F. (1952), Acta med scand.' Suppl., 266, 233

BRUCK, E., RAPOPORT, M., and RUBIN, M. I. (1954), f. cling Invest., 33, 699 .

CHARLTON, D., LATNER, A. L., PLATT, J. W., SMART, G. A., THOMMPON, R. B., and WALKER, W. (1957) (In Press).

DEBRE, R., ROYER, P., LEVEQUE, B., and MINOR, Z. (1956) Sem. Hop. Paris, 32, 263.

ELLIS, A. (1942), Lancet, i, I.

FANCONI, G., KOUSMINE, C., FRISCHKNECHT, W. (195 I Helv. paediat. Acta, 6, 219.

FARNSWORTH, E. B. (1950), Clinical ACTH Conference (Ed. mote), J. \& A. Churchill Ltd., 1950, p. 297

HAMILTON, M., PICKERING, G. W. FRASER ROBERTS J. A., and SOWRY, G. S. C. (1954), Clin. Sci., 13, I I and 376

JANEWAY, C. A., MOLL, G. H., ARMSTRONG, S. H. Jr N WALLACE, W. M., HALLMẢN, N., and BARNESS, L. ÄW (1948), Trans. Ass. Amer. Phys., 6r, ro8.

KARK, R. M., MUEHRCKE, R. C., PIRANI, C. L., and POLLAK, V. E. (1955), Ann. intern. Med., 43, 807.

KIMMELSTEIL, P., and WILSON, C. (1936), Amer. F. Path. $12,83$.

LANG,E K., GRAIG, F., OBERMAN, J., SLOBODY, L., OGURᄃ G., and IOCASTO, F. (195I), Arch. intern. Med., 88, 433.

LANGE, K., SLOBODY, L., and STRANG, R. (1953), Proc. Soc. exp. Biol. (N.Y.), 82, 315 .

LUETSCHER, J. A., Jr., DEMING, Q. B., JOHNSON, B. B., \&ी PIEL, C. F. (1953), F. Amer. med. Ass., 153, 1,236.

MASUGI, M. (1933-34), Beitr. path. Anat., 92, 429.

MERRILL, A. J., WILSON, J., and TIMBERLAKE, LCô (1954), Arch. intern. Med., 94, 925.

METCOFF, J., KELSEY, W, RANCE C. P and JANEWAY C. A. (195r), 'Proc. of Second Clinical ACTH Conference (Ed. mote), 2, 148, J. \& A. Churchill Ltd.

SOSHEA, J. W., and FARNSWORTH, E. B. (1951), F. Lab. clin? med., 38, 414

\section{RUTHIN CASTLE, NORTH WALES}

A Clinic for the diagnosis and treatment of Internal Diseases (except Mental or Infectious Diseases). The Clinic is provided with a staff of doctors, technicians and nurses.

The surroundings are beautiful. The climate is mild. There is central heating throughout. The annual rainfall is 30.5 inches, that is less than the average for England.

The Fees are inclusive and vary according to the room occupied.

For particulars apply to THE SECRETARY, Ruthin Castle, North Wales.

Tolegrams: Castle, Ruthin

Telephone: Ruthin 66

Bibliography continued from page 324-F. Dudley Hart, M.D., F.R.C.P. treated conservatively, appears to be more common in steroid treated cases.

\section{BIBLIOGRAPHY}

BALL, J. (i954), Ann. rheum. Dis., 13, 277. DUBOIS, E. L. (1956), Ann. intern. Med., 45, 163. HARGRAVES, M. M., RICHMOND, H., and MORTON, Ré
(1948), Proc. Mayo Clin., 23, 25. KEMPER, J. W., BAGGENSTOSS, A. H., and SLOCUMB, C. H (1957), Ann. intern. Med., 46, 83 I.

MUEHRCKE, R. C., KARK, R. M., PIRANI, C. L., and POLLAK, V. E. (1957), Medicine, 36, x. REPORT OF THE MEDICAL RESEARCH COUNCIL (1957), Brit. med. $\mathcal{F}$., 1,608 .

SLOCUMB, C. H. (x 953), Proc. Mayo Clin., 28, 655. 